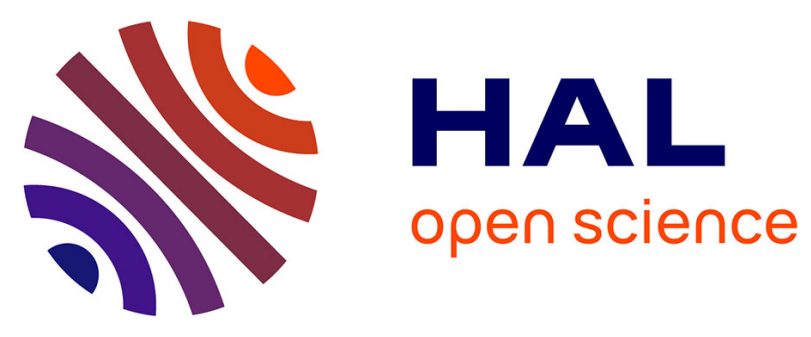

\title{
Content Unification: A Trend Reshaping the iTV Ecosystem
}

Jorge Abreu, Pedro Almeida, Sílvia Fernandes, Ana Velhinho, Ana Rodrigues

\section{To cite this version:}

Jorge Abreu, Pedro Almeida, Sílvia Fernandes, Ana Velhinho, Ana Rodrigues. Content Unification: A Trend Reshaping the iTV Ecosystem. Esteban Clua; Licinio Roque; Artur Lugmayr; Pauliina Tuomi. 17th International Conference on Entertainment Computing (ICEC), Sep 2018, Poznan, Poland. Springer International Publishing, Lecture Notes in Computer Science, LNCS-11112, pp.297300, 2018, Entertainment Computing - ICEC 2018. 10.1007/978-3-319-99426-0_33 . hal-02128632

\section{HAL Id: hal-02128632 \\ https://hal.inria.fr/hal-02128632}

Submitted on 14 May 2019

HAL is a multi-disciplinary open access archive for the deposit and dissemination of scientific research documents, whether they are published or not. The documents may come from teaching and research institutions in France or abroad, or from public or private research centers.
L'archive ouverte pluridisciplinaire HAL, est destinée au dépôt et à la diffusion de documents scientifiques de niveau recherche, publiés ou non, émanant des établissements d'enseignement et de recherche français ou étrangers, des laboratoires publics ou privés.

\section{(c)(1)}

Distributed under a Creative Commons Attribution| 4.0 International License 


\title{
Content unification: a trend reshaping the iTV ecosystem
}

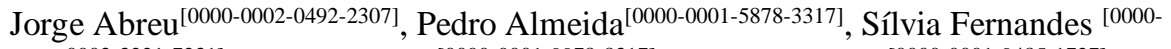 \\ 0003-3221-7231], Ana Velhinho ${ }^{\text {[0000-0001-9978-8317] }}$, Ana Rodrigues ${ }^{[0000-0001-9485-1727]}$ \\ University of Aveiro, DigiMedia, Portugal \\ \{jfa, almeida, silvia.fernandes, ana.velhinho, ana.rodrigues\}@ua.pt
}

\begin{abstract}
Changes in the viewer's habits, such as getting linear and nonlinear content, anytime and anywhere, are reshaping the behaviors of watching TV. In this context, many commercial stakeholders, of both Managed Operated Networks (MON) and Over-the-Top solutions (OTT), have been offering new content unification features supported by innovative user interfaces, including natural language interaction, to turn the TV viewing experience more pleasurable and engaging. Beyond the providers' commercial interests of preserving their walled gardens, the need for retention of customers is pushing channels, operators and OTT players to match each other's offers. Solutions are multiplying on leading services towards a personalized experience that aggregates several sources of content in the same interface, enriched with emergent interaction models such as voice control. Such industry trends, paired with empirical academic research, support the development of new unification-based UI solutions, that promise to have a central role in the future of the TV.
\end{abstract}

Keywords: iTV industry, Unification, User Interface, OTT, Voice Interaction

\section{Introduction}

Over the last decade, we have been witnessing a revolution in the Interactive Television (iTV) domain, with the emergence of new content delivery technologies and the increasing penetration of Over-the-Top (OTT) content. The result is the blurring of boundaries, between linear and non-linear content, the improvement of the features, and a considerable impact on the viewer's behaviors [1-3]. While providing flexibility regarding content access and consumption, new technologies have diversified interaction models and User Interfaces (UI). To map the current iTV domain, two surveys conducted under the scope of R\&D projects developed in partnership with an IPTV industry player, gathered data about interaction models [4], and UI design trends [5]. This paper increments the referred studies with recent releases. After this introduction, the next section presents the state of the art of the unification trend with a focus on the iTV UIs. The third section introduces an empirically validated iTV prototype for the unification of content, developed under an R\&D consortium. Finally, the main contributions of this study are drafted in the conclusion section. 


\section{Current unification trends in iTV Industry}

Recently, online players have developed niche business models relying on OTT streaming technology. To face these OTT newcomers, cable Pay-TV subscriptions have started to offer additional On-Demand services. Despite the fast growth of such players, limitations on getting traditional TV channels and live content [6] kept them from taking over the TV market. Those restrictions prevent a seamless UX, perpetuating a behavior of using multiple apps displaying different settings and UIs. The lack of integrated search and cross-source recommendations is also a limitation that leads to users having a scattered audiovisual consumption across devices. The interdependent dynamics between channels and Pay-TV operators and OTT providers is bringing both sides closer together in favor of more balanced solutions regarding a personalized and content-first viewing experience. With the aim to address the most recent unification trend in the iTV domain (2017-2018 releases), this document highlights prominent operator-based versus OTT-based solutions that offer cutting-edge approaches to unification.

\subsection{Sky Q}

A pioneer unification partnership between UK cable company Sky and Netflix could be the beginning of a paradigmatic change. In March 2018, Sky announced that the complete Netflix catalog would be made available to their Sky Q customers in a single, unified user interface ${ }^{1}$, allowing the user to switch between live and Netflix content seamlessly (see Fig. 1). This is a significant example of how the iTV domain is becoming more and more intertwined with an inescapable unification of sources, with both cable and OTT providers coming to terms with the benefits of a cross-content approach.

\section{$2.2 \quad$ Hulu}

Hulu has also rebranded its VOD platform to include a new set of live content and channels alongside their original content ${ }^{2}$. Hulu Live supports a "Lineup" area that presents personalized content from their on-demand and live content to each profile (see Fig. 1). Although it offers on-demand, what truly differentiates Hulu is the integration of live channels in a distinctive graphical interface. A traditional grid is replaced by lists, with contemporary gradients act as filters, setting Hulu apart from other platforms.

\footnotetext{
${ }^{1}$ Sky Group, http://bit.ly/2LcigCg, last accessed 2018/06/01.

${ }^{2}$ Hulu Homepage, https://www.hulu.com/live-tv, last accessed 2018/06/01.
} 


\subsection{YouTube TV}

Offering a device-independent proposal, YouTube launched the YouTube TV app in $2017^{3}$. While the app started out as a mobile solution to the new ways of watching TV or online audiovisual content, by combining live channels to its ever-growing catalog of user-generated content, YouTube TV has become a stand-alone product in its commercial offer of online and live content (see Fig. 1). As a streaming platform, the YouTube TV is becoming a key app for other devices, as it is now available for mobile, browser, or as an app for smart TVs. Highly flexible but limited to the USA, it is an ambitious product that will continue to grow.

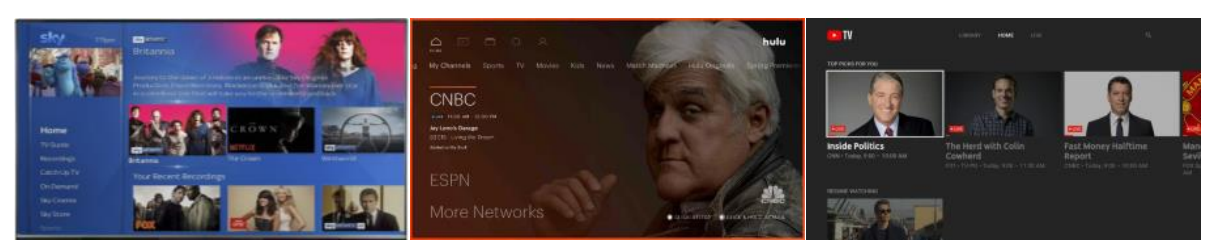

Fig. 1. Sky Q (left), Hulu (center), YouTube TV app for Roku devices (right)

\section{An operator-based prototype for content unification}

The product of the synergy between industry and academy, the UltraTV prototype targets the new TV generation focused on the unification and personalization [7, 8]. The prototype (Fig. 2) combines on the same UI and UX, TV content and OTT content (YouTube, Facebook videos, Netflix). With a MON-based framework supported by the operator's offer, it provides a unified access to a diversified bundle of content sorted by genres and sources. Content is displayed on a card-based grid with axis navigation and a fluid blob menu redirecting to the system's main features: "My Content" area (favorites and keep watching), filtering, profiles, unified search, and settings. Crosscontent recommendations are also offered to foster the discovery of content.

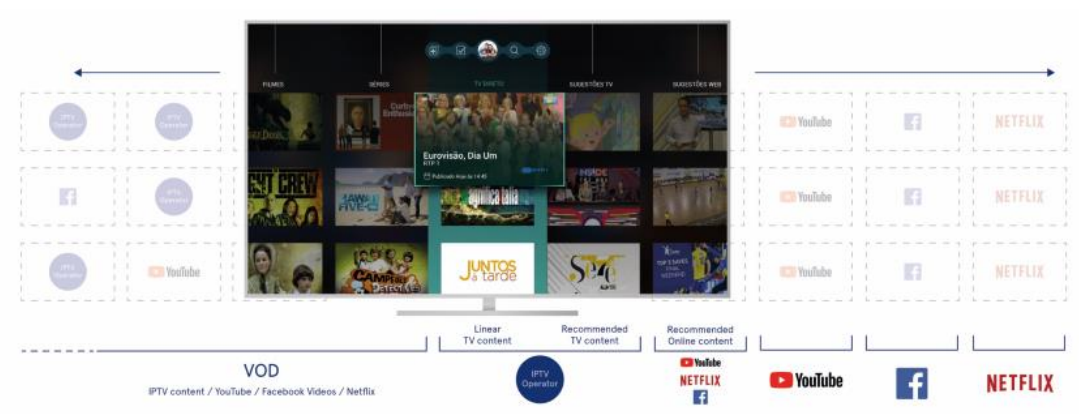

Fig. 2. UltraTV home screen interface architecture

\footnotetext{
${ }^{3}$ YouTube TV Homepage, http://www.tv.youtube.com, last accessed 2018/06/01.
} 


\section{Conclusion}

Recent releases in the iTV industry confirm growing expectations towards personalization and unification features, favoring the aggregation of sources, merging linear with non-linear videos. The single UI horizontal unification shows a different path from existing solutions that provide content in proprietary apps. While operatorbased solutions strive to accommodate in their offers streaming services (e.g. Sky Q), OTT players steadily conquer the TV market by adding live broadcast confined by restrictions (e.g. Hulu, YouTube TV). Without a fully integrated solution available on the market, research projects are developing solutions that envision enhanced viewing experiences boosted by profile-based recommendations and content discovery on a single UI. Supported by feedback of end-users and recognizing industry trends, these contributions may provide valuable user and content-centered insights agnostic to players' interests to push the next generation of television, including advanced interaction by natural language (as the project CHIC - Cooperative Holistic view on Internet and Content).

\section{Acknowledgments}

This paper is a result of the CHIC - Cooperative Holistic for Internet and Content (grant agreement number 24498), funded by COMPETE 2020 and Portugal 2020 through the European Regional Development Fund (FEDER).

\section{References}

1. Abreu, J., Nogueira, J., Becker, V., Cardoso, B.: Survey of Catch-up TV and other time-shift services: a comprehensive analysis and taxonomy of linear and nonlinear television. Telecommun. Syst. 64, 57-74 (2017).

2. Nielsen-Company: Screen wars: The battle for eye space in a TV-everywhere world. New York (2015).

3. Ericsson-Consumerlab: TV and Media 2017: A consumer-driven future of media. Stockholm (2017).

4. Silva, T., Almeida, P., Jorge, A., Oliveira, E.: Interaction Paradigms on iTV: a survey towards the future of television. In: The 9th International Multi-Conference on Complexity, Informatics and Cybernetics. IMCIC, Orlando (2018).

5. Abreu, J., Almeida, P., Varsori, E., Fernandes, S.: Interactive television UI : Industry trends and disruptive design approaches. In: Proceedings of 6th Iberoamerican Conference on Applications and Usability for Interactive TV. pp. 213-224. UA Editora, Aveiro (2017).

6. Waterman, D., Sherman, R., Wook Ji, S.: The economics of online television: Industry development, aggregation, and "TV Everywhere." Telecomm. Policy. 37, 725-736 (2013).

7. Almeida, P., Jorge, A., Fernandes, S., Oliveira, E.: Content Unification in iTV to Enhance User Experience: The UltraTV Project. In: Proceedings of the ACM International Conference on Interactive Experiences for TV and Online Video - TVX '18. ACM, Seoul (2018). 8. $\quad$ Almeida, P., Abreu, J., Silva, T., Guedes, R., Oliveira, D., Cardoso, B., Dias, H.: UltraTV: an iTV content unification prototype. In: Proceedings of the ACM International Conference on Interactive Experiences for TV and Online Video - TVX '18. ACM, Seoul (2018). 